\title{
Morphometric Study on the Digestive System of the Wild Gray Squirrel (Sciurus carolinensis).
}

\section{J.O. Nzalak ${ }^{1}$, N. Wanmi ${ }^{2}$ and M. O. Samuel ${ }^{2}$}

${ }^{1}$ Department of Veterinary Anatomy, Faculty of Veterinary Medicine, Ahmadu Bello University, Zaria, Kaduna State, Nigeria.

${ }^{2}$ Department of Veterinary Anatomy, College of Veterinary Medicine, University of Agriculture, Makurdi, Benue State, Nigeria.

\section{With 1 figures \& 2 tables $\quad$ Received July, accepted for publication August 2015}

\section{Abstract}

The present study was conducted on Five apparently healthy wild gray squirrel of different ages and sexes. The various parts of the digestive system of each animal were dissected out and were weighed and measured. The small intestine was observed to have the highest mean weight $(5.86 \pm 0.8 \mathrm{~g})$ followed by the large intestine $(2.98 \pm 0.49 \mathrm{~g})$. Of all the intestinal segments, the duodenum was observed to have the highest mean weight $(2.49 \pm 0.32 \mathrm{~g})$ followed by the jejunum $(2.03 \pm 0.29$ g) The mean length of the gastrointestinal tract (GIT) was observed to be $136.10 \pm 10 \mathrm{~cm}$ with the small intestine having a mean length value $90.73 \pm 10.31 \mathrm{~cm}$ and was observed to have the longest segment, followed by the large intestine $(31.54 \pm 2.25 \mathrm{~cm})$. Out of all the intestinal segments (small and large) the jejunum was observed to have the longest segment (32.39 \pm 4.19

J. Vet. Anat. $\mathrm{cm})$ followed by the ileum (27.93 \pm $4.31 \mathrm{~cm})$ and the duodenum (25.53 $\pm 2.67 \mathrm{~cm}$ ), respectively. The liver was observed to have the mean weight (18.36 $\pm 0.77 \mathrm{~g})$ and had no gall bladder. The caecum had the least value of the segments of the large intestine; the colon and rectum had almost the same mean length $(14.64 \pm 1.84 \mathrm{~cm}$ and $14.54 \pm 0.60$ $\mathrm{cm}$, respectively). The absence of gallbladder will have a direct effect on the emulsification of fats. The short length of the colon and rectum indicates that no digestion takes place in those regions.

Keywords: Macrometric, Digestive System, Gray Squirrel (Sciurus carolinensis)

\section{Introduction}

The squirrel is a member of the Order, Rodentia, Family, Sciuridae, Genus, sciurus (Andren, 1994). They are either arboreal, ground- 
dwelling species or may possess both. They can be distinguished from other species by their size and color. Male and female squirrels are approximately the same size, typically weighing between 270 and 360 grams, but some of the species may reach up to 720 grams Adams (1976). The gray squirrel varies in color from gray to brownish- gray with a white underbelly and white tips on the tail hairs.

Squirrels are known to having large eyes, relatively small ears, short fore limbs for grasping food materials and long hind limbs adapted for leaping. Their amazing ability to turn their hind feet through $180^{\circ}$ gives them a strong grip and allows them move down a tree head first (Flyger and Gates, 1982a).

Squirrels are found in most woodland habitats, forests, around parks, gardens and farmland.

In other to augment protein deficiency, there is a need to enhance food production in developing countries as most people live under deplorable conditions with shortage in protein rich-rich food in African countries, (FAO, 2002a). This animal is been hunted and sold as bush meat which serves as delicacy and steady source of income for rural dwellers (Ibrahim and Abdu, 1992).

J. Vet. Anat.
Works done on the digestive system of some rodents in this part of the country include those of the African giant rat (AGR) (Ali, et al., 2008; Byanet et al., 2010, Nzalak et al., 2010 and Nzalak et al., 2012) and the Grasscutter (Byanet et al., 2008),. However, there is deficiency in the available literatures dealing with the anatomy of the digestive system of the squirrel. Our present study is being carried out in order to serve as a baseline data.

\section{Materials and Methods}

\section{Experimental Design}

Five apparently healthy wild gray squirrels (Sciurus carolinensis) of both sexes were captured using metal traps around Giwa village, Kaduna state, Nigeria were used for this study. Sex difference was not taken into consideration. The animals were transported to the Department of Veterinary Anatomy, Faculty of Veterinary Medicine, $A B U$, Zaria, they were then transferred into a standard laboratory rat cages and kept in the animal unit of the Department, and allowed to stay for two weeks to acclimatize. The animals were later sacrificed according to the methods of Adeyemo and Oke (1990) and placed on a lateral recumbency. An incision was made on the skin and fascia at the base of the ear and the caudal border of the mandibles, and the parot- 
id and mandibular salivary glands dissected out. The mouth of each of the squirrel was opened and a cut was made through the muscles. The articulating surfaces of the mandibles were dislocated using a handsaw to show the complete tongue. Each tongue was dissected out and its weight and length recorded. Another incision was made from the first cervical region up to the level of the pelvic region with the rat lying on a dorsal recumbency to show the esophagus and the content of the GIT. The entire GIT was exteriorized and the contents removed starting from the esophagus and the various segments of the stomach, the small intestine (duodenum, jejunum and ileum), the large intestine (caecum, colon and rectum), liver were weighed and their lengths measured and recorded.

\section{Morphometric study}

The value of both length and weight of the digestive segments are recorded in grams and centimeters, respectively. All these measurement were done using a Fatzun balance (model P141 with a sensitivity of $0.01 \mathrm{gm}$.), a ruler, vernier caliper and thread (in $\mathrm{cm}$ ), respectively.

\section{Statistical Analysis}

Mean \pm Standard Error of Mean (Mean \pm SEM) using Statistical Package for Social Science (SPSS)
Version 17 was used in finding values for weights and length. Values $P<0.05$ was considered significant.

\section{Results}

The mean body weight of the wild gray squirrel was $380.04 \pm 46.00 \mathrm{~g}$. The mean weight of the GIT was recorded to be $37.92 \pm 3.83 \mathrm{~g}$ which constituted about $9.97 \%$ of the total body weight and the correlation was significant with that of the total body weight. The esophagus had a mean weight of $0.50 \pm 0.08 \mathrm{~g}$ and accounted for $0.13 \%$ of total body weight. The mean weight of the stomach and small intestine were $1.59 \pm 0.36 \mathrm{~g}$ and $5.86 \pm 0.86 \mathrm{~g}$, which accounted for $0.42 \%$ and $1.54 \%$ respectively. The mean weight of the various segments of the small intestine: duodenum, jejunum and ileum were observed to be $2.49 \pm 0.32 \mathrm{~g}, 2.03 \pm 0.29 \mathrm{~g}$ and $1.67 \pm 0.27 \mathrm{~g}$ respectively. The duodenum had the highest mean body weight $(0.66 \%)$ followed by the jejunum $(0.53 \%)$ and the ileum $(0.43$ $\%)$, (Table 1).

The mean weight of the large intestine was observed to be $2.98 \pm$ $0.49 \mathrm{~g}$ which accounted for $0.78 \%$ of the total body weight. The large intestine consisted of the caecum, colon and rectum with their mean weights of $0.44 \pm 0.16 \mathrm{~g}, 1.76 \pm$ $0.30 \mathrm{~g}$ and $0.61 \pm 0.09 \mathrm{~g}$, respec- 
tively. The colon had the highest percentage of $0.46 \%$ followed by the caecum, $0.12 \%$ and rectum, 0 . $16 \%$ (Table 1). The correlation between weights of large intestine to that of the body weight was significant (Table 1).

The small intestine was found to have the highest mean weight (5.86 $\pm 0.86 \mathrm{~g}$ ) followed by the large intestine $(2.98 \pm 0.49 \mathrm{~g})$. Of all the digestive glands, the liver was observed to have the highest mean weight $(18.36 \pm 0.77 \mathrm{~g})$ and accounted for $48.26 \%$ of the total body weight (Table 1). The correlation between the weights of the liver and that of the body was observed to be significant. The mean weights of parotid and mandibular salivary glands were observed to be $0.19 \pm 0.05 \mathrm{~g}$ and $1.09 \pm 0.24 \mathrm{~g}$ and accounted for $0.10 \%$ and $0.05 \%$ respectively. The correlation between the spleen and that of the body weight was observed to be significant.

The length of the gastrointestinal tract was observed to be $136.10 \pm$ 14. $74 \mathrm{~cm}$, while the mean length of the esophagus was observed to be $6.06 \pm 0.74 \mathrm{~cm}$ accounting for 5.45 $\%$ of the total length of the gastrointestinal tract. The length of the stomach was observed to be 136.10 $\pm 14.79 \mathrm{~cm}$ accounting for $2.94 \%$ of the total body length. The length of

J. Vet. Anat. the small intestine was observed to be $90.73 \pm 10.31 \mathrm{~cm}$, this value accounted for $66.18 \%$ of the total length of the GIT. The length of the various segments of the small intestine: duodenum, jejunum and ileum were $25.53 \pm 2.67 \mathrm{~cm}, 32.39 \pm 4.19$ $\mathrm{cm}$ and $27.93 \pm 4.31 \mathrm{~cm}$. These values accounted for $19.97 \%$, $24.80 \%$ and $21.52 \%$, of the total large intestine length respectively. The jejunum was observed to be the longest segment followed by the ileum and then the duodenum ( $\mathrm{Ta}$ ble 2).

The length of the large intestine and its segments (caecum, colon and rectum) were observed to be 31.54 $\pm 2.25 \mathrm{~cm}, 2.48 \pm 0.17 \mathrm{~cm}, 14.64 \pm$ $1.84 \mathrm{~cm}$ and $14.54 \pm 0.60 \mathrm{~cm}$, respectively. These accounted for $24.67 \%, 2.86 \%, 10.77 \%$ and 10.68 $\%$ of the total large intestine length respectively. The colon and rectum had similar length, while the caecum was observed to be the shortest (Table 2).

\section{Discussion}

In the current work the mean body weight of the Grasscutter was observed to be $380.04 \pm 46.00 \mathrm{~g}$. This value was less than those of the AGR (lbe, et al. 2010) and Grasscutter (Byanet et al., 2008), but greater than those of the laboratory rats (Rudolf and Stromberg 
1976). The whole digestive system accounted for $9.97 \%$ of the total body weight and it consisted of the esophagus, stomach, small and large intestines and the accessory glands.

The mean weight of the stomach was observed to be $1.59 \pm 0.36 \mathrm{~g}$ which accounted for $0.42 \%$ contrary to $0.5 \%$ of the total body weight that was observed in the laboratory rat (Rudolf and Stromberg 1976). Byanet, et al. (2010), in their study reported a higher value of the stomach of the AGR $(28.81 \pm 0.93 \mathrm{~g})$ and consisted of two compartments (glandular and non-glandular) attached at a particular point by the esophagus and duodenum, as opposed to one in the squirrel.

The mean weight of the small intestine was observed to be $5.86 \pm 0.86$ $\mathrm{g}$ with the duodenum having the highest mean weight $(2.49 \pm 0.32 \mathrm{~g})$ and accounted for $0.66 \%$ of the total body weight. The mean weight of the large intestine was observed to be $2.98 \pm 0.49 \mathrm{~g}$ with the caecum having the least mean value $(0.44 \pm$ $0.16 \mathrm{~g}$ ) and accounted for $0.12 \%$. This in contrast with the findings by Nzalak et al. (2012) on African giant rat in which the rectum had the least mean value.
The mean weight of the liver accounted for $48.26 \%$ of the total body weight. Reports by other researchers have shown that the weight of the liver is higher than other accessory organs in domestic animals. Correlation between weights of the liver to that of the body weight was significant at $\mathrm{P}<$ 0.05 which means that as the body weight increases, there is a corresponding increase in the weight of the liver.

The whole length of the GIT of the gray squirrel of this study was $136.10 \pm 14.79$ with the small intestine accounting for $66.16 \%$. It was observed to be higher than the value for large intestine. This finding is in agreement with that of Nzalak et al. (2012), where they observed the small intestine to be longer than that the large intestine in most rodents. Byanet et al. (2008) observed that in the Grass-cutter, the colon was the longest of the intestinal segments (small and large intestines).In the present study, the jejunum was observed to have the longest intestinal segments. The mean length of the blind-like end caecum in this present study disagrees with those reported by Ali et al. (2008) and Byanet et al. (2010) for the AGR and Cathy (2006) for the rabbit. These may be attributed to their feeding habits. While Grasscutter 
feed on elephant grass, rabbits are said to be coprophage on their faeces and they need a developed caecum which will serves as a fermentation vat. The length of the colon and rectum are relatively the same as opposed to other rats. Nzalak (2010) observed the presence of gallbladder in the AGR contrary to what was observed in this study. In the present study the gallbladder was observed to be absent, this would affect the emulsification of fat (Armand et al., 1994)

\section{Conclusion}

The current results recommended a spotlight on some anatomical parameters of the digestive system of the wild gray squirrel in Nigeria. We reported that the lengths of colon and rectum were relatively the same, but the mean weight of the colon was higher. This study was able to report the absence of the gall bladder in the squirrel.

\section{Acknowledgement}

I acknowledge great contributions from and technical assistance offered by Mr. Jangbar Nicodemus and Mr. Bamidele all of A.B.U, Zaria. Their unquantifiable inputs toward this work are appreciated.

\section{References}

Adams, C. E. (1976): Measurements and characteristics of fox squirrels, Sciurus niger rufiventer, home ranges. Amer.Midl. Nat. 95: 211-215.

Adeyemo, O. and Oke, B.O. (1990): Comparism of the testicular and epididymal proteins of the African giant rat (Cricetomys gambianus) and laboratory rats. Tropical Veterinarian, 8:17-27

Armand, M, Borel, P, Dubois, C (1994). Characterization of emulsions and lipolysis of dietary lipid in human stomach. American Journal Physiology, 266: G372-381.

Ali, M.N., Byanet, O., Salami, S.O., Imam, J., Maidawa, S.M., Umosen, A.D and Nzalak, J.O. (2008): Gross anatomical aspect of gastrointestinal tract of the wild African giant rat (Cricetomys gambianus). Journal of. Scientific Research and Essay, 3: 518-520.

Byanet, O., Nzalak, J.O., Salami, S.O., Nwaogu, I.C., Bosha., J.A., Umosen, A.D., Ojo, S.A. and Obadiah, H.I. (2008): Macroscopic studies of the gastrointestinal tract of the African grasscutter (Thyronomys Swinderianus). Medwell Online Journal of Veterinary Research, 2: 17-21. 
Byanet, O., Salami, S.O., Ali, M.N., Imam, J., Maidawa, S.M., Umosen, A.D., Alphonsus, C. and Nzalak, J.O. (2010): The macro-anatomy of the stomach of the wild African pouched rat (Cricetomys gambianus). Sahel Journal of Veterinary Science, 9: 69-72.

Cathy, A.J. (2006): Anatomy and Physiology Of The Rabbit and Rodent Gastrointestinal System. Eastside and Exotic Medical Centre, PLLC $100^{\text {th }}$ Aevnue NE, WA 98034, USA, PP. 14

Collett, T. S., Cartwright, B. A and Smith, B. A. (1986): Landmark learning and visual-spatial memories in gerbils Journal of Comparative Physiology, 8 35-851.

FAO (2002): Food for all. Statistical database. http:www.agriza [Date of access 3rd may 2002].

Flyger, V., and J. E. Gates. (1982): Fox and gray squirrels. Pages 209229 in J. A. Chapman and G. A. Feldhamer, eds. Wild mammals of gambianus-Waterhouse). Journal of Veterinary Anatomy, 3: 55-64.

Ibe, C.S., Onyeanusi, B.I., Salami, S.O., Ajayi, I.E., Nzalak, J.O. (2010): ON the structure of spleen of the African gaint rat pouch (Cricetomys gambianus, Waterhouse)

Medwell Journal of Veterinary Research. 3(4): 70- 71.

Ibrahim, M.A. and Abdu, P.A. (1992): Ethnoagro-veterinary perspective of poultry management health and reproduction among Hausa /Fulani of rural Nigeria. Veterinary Medical Association, Pp. 172-181.

Kanril, A. C. and Balda, R .C. (1985) : Achieves of recovery and spatial memory in Clark's nutcracker (Nucifraga columbianus). Journal of Experimental Psychology, Animal Behave Procedings, II, 95.

McQuade, D.,Willians, E .H. and Eichenbaum H, B. (1986): Cues used for localizing food by the grays quirrel (Sciurus carolinensis). Ethology, 7 2, 22-30. North America: biology, management, and economics. The Johns Hopkins Univ. Press, Baltimore.

Nzalak,, J.O. (2010): Anatomical and histological studies of the digestive system of the African giant rat (Cricetomys gambianus-Waterhouse). Ph.D. Thesis, Ahmadu Bello University, Zaria.

Nzalak, J.O, Onyeanusi, B.I. and Salami, S.O. (2012): Macrometric study of the digestive system of the African Giant Rat (Cricetomys gambianus, WaterHouse 1840). Euro- 
pean Journal of anatomy, 16(2): 113-118.

Rudolf, H. and Stromberg, M.W. (1976): Digestive System. In: anatomy of the laboratory rat, Williams company, pp. 43-51.
Steele, M. A. and Koprowski, J. L. (2001): North American tree squirrels. Washington: Smithsonian Institution Press. Washington, DC, pp. 224.

\section{Corresponding Author}

Wanmi, N; Department of Veterinary Anatomy, College of Veterinary Medicine, University of Agriculture, Makurdi, Benue State, Nigeria.

e-mail: nathnie/wanmi2014@gmail.com

Table (1): Morphometry of the Digestive System of the Wild Gray Squirrel. $\mathbf{n}=\mathbf{5}$.

\begin{tabular}{|l|c|c|c|c|}
\hline \multicolumn{1}{|c|}{ Weights (g), } & $\begin{array}{c}\text { Min. } \\
\text { Value }\end{array}$ & Max.Value & Mean \pm SEM & $\begin{array}{c}\% \text { Body } \\
\text { Weight }\end{array}$ \\
\hline Body weight/g & 242.83 & 487.74 & $380.04 \pm 46.00$ & \\
\hline Weight of GIT/g & 29.90 & 50.72 & $37.92 \pm 3.83^{* *}$ & 9.97 \\
\hline Weight of esophagus & 0.22 & 0.70 & $0.50 \pm 0.08$ & 0.13 \\
\hline Weight stomach & 1.03 & 2.99 & $1.59 \pm 0.36^{* *}$ & 0.42 \\
\hline Weight small intestine & 3.90 & 8.78 & $5.86 \pm 0.86^{* *}$ & 1.54 \\
\hline Weight duodenum & 1.84 & 3.39 & $2.49 \pm 0.32$ & 0.66 \\
\hline Weight jejunum & 1.06 & 2.84 & $2.03 \pm 0.29$ & 0.53 \\
\hline Weight ileum & 1.00 & 2.21 & $1.67 \pm 0.27$ & 0.43 \\
\hline Weight of large intestine & 1.60 & 4.51 & $2.98 \pm 0.49$ & 0.78 \\
\hline Weight of caecum & 0.90 & 0.81 & $0.44 \pm 0.16$ & 0.12 \\
\hline Weight of colon & 1.06 & 2.63 & $1.76 \pm 0.30$ & 0.46 \\
\hline Weight of rectum & 0.28 & 0.86 & $0.61 \pm 0.09$ & 0.16 \\
\hline Weight of tongue & 0.61 & 1.94 & $1.25 \pm 0.22$ & 0.33 \\
\hline Weight of parotid gland & 0.25 & 0.53 & $0.39 \pm 0.05$ & 0.10 \\
\hline Weight of mandibular gland & 0.10 & 0.39 & $0.19 \pm 0.05$ & 0.05 \\
\hline Weight of liver & 15.88 & 20.20 & $18.36 \pm 0.77$ & 48.26 \\
\hline Weight of spleen & 0.20 & 1.50 & $1.09 \pm 0.24^{*}$ & 0.29 \\
\hline
\end{tabular}

*; Significant Values, **; Non Significant Values, SEM; Standard Error of Mean 
Table (2): Morphometric of the Digestive System of the Wild Gray Squirrel. $\mathbf{n}=5$.

\begin{tabular}{|l|c|c|c|c|}
\hline \multicolumn{1}{|c|}{ Length $(\mathrm{cm})$} & $\begin{array}{c}\text { Min. } \\
\text { value }\end{array}$ & $\begin{array}{c}\text { Max. } \\
\text { value }\end{array}$ & Mean \pm SEM & \% body weight \\
\hline Length of GIT/ cm & 87.69 & 173.19 & $136.10 \pm 14.79^{\prime \prime}$ & 100 \\
\hline Length of Esophagus & 3.90 & 8.14 & $6.06 \pm 0.74$ & 5.45 \\
\hline Length Stomach & 2.33 & 6.01 & $4.00 \pm 0.61$ & 2.94 \\
\hline Length of Small Intestine & 56.81 & 120.71 & $90.73 \pm 10.31$ & 66.18 \\
\hline Length of duodenum & 18.49 & 31.10 & $25.53 \pm 2.67$ & 19.76 \\
\hline Length of jejunum & 20.47 & 46.20 & $32.39 \pm 4.19$ & 24.80 \\
\hline Length of ileum & 17.68 & 43.45 & $27.93 \pm 4.31$ & 21.52 \\
\hline Length of large intestine & 24.61 & 38.27 & $31.54 \pm 2.25$ & 24.67 \\
\hline Length of caecum & 2.02 & 2.96 & $2.48 \pm 0.17$ & 2.86 \\
\hline Length of colon & 9.01 & 19.20 & $14.64 \pm 1.84$ & 10.77 \\
\hline Length of rectum & 13.51 & 16.01 & $14.54 \pm 0.60$ & 10.68 \\
\hline Length of tongue & 1.21 & 4.45 & $2.86 \pm 0.61^{* *}$ & \\
\hline Length of parotid gland & 1.11 & 2.25 & $1.54 \pm 0.23$ & \\
\hline Length of mandibular gland & 1.01 & 1.95 & $1.27 \pm 0.17^{* *}$ & \\
\hline
\end{tabular}

*; Significant Values, ${ }^{* *}$; Non Significant Values, SEM; Standard Error of Mean 


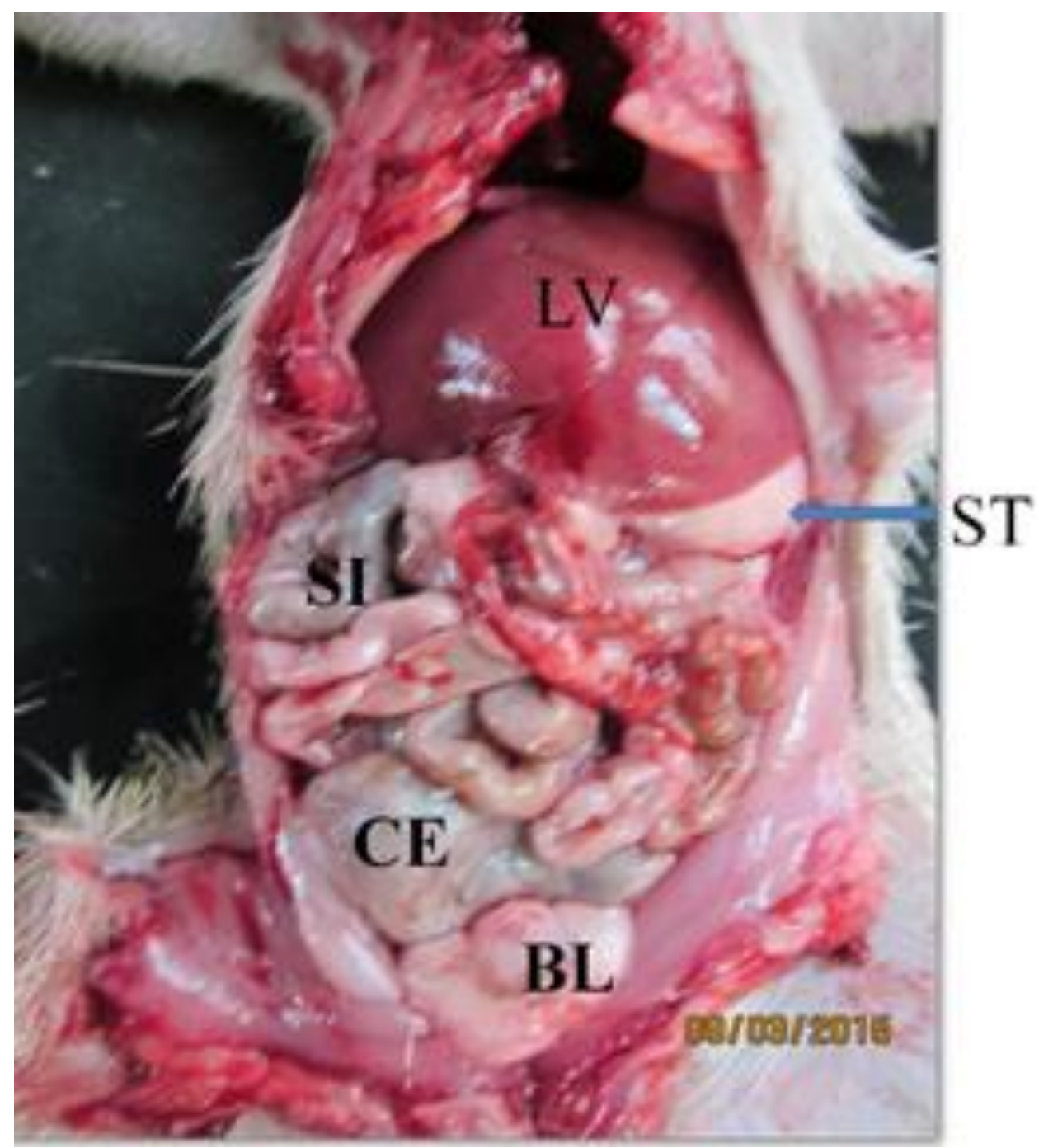

Fig (1): Ventral view of the opened abdomen of the wild gray squirrel showing: LV Liver, ST Stomach, SI Small intestine, CE Cecum, BL Urinary bladder. 